\title{
THE NATIONAL RESEARCH COUNCIL OF CANADA
}

$\mathrm{T}$

HE review of activities of the National Research Council of Canada for the year ending March 1940, which has now appeared, includes the report of the president, together with reports of the divisions and sections and reports of co-operative investigations, including the associate, joint and special committees.*

The president's report, referring to the re-alignment of work through the effect of the War, points out that many of the studies that were being carried out in peace-time proved of equal or greater importance in war-time, and the change over to a war-time programme involved very little departure from existing procedure. The Aeronautical Committee since the outbreak of war has been occupied almost exclusively on urgent military aviation problems, while the Radio Committee has undertaken a greatly enlarged and intensive programme directed exclusively by military considerations. With the outbreak of war, the Metrological Laboratory was considerably expanded to undertake the standardization of munition gauges. Scientific work of the Department of National Defence for the Services has included problems relating to the mechanical equipment, and other problems, of naval craft, such as the design and performance of hulls and the investigation of means of offence and defence in sea warfare. Research work for the Militia Service has covered war supplies, munitions manufacture, the examination of explosives and the provision of supplies for the troops, while for the Air Force the facilities of the Aeronautical Laboratories are used to determine the practicability of new designs of aircraft and engines, improvement in technique in construction and flight, engine performance and the effect of modifications in fuels and lubricants, etc. Other laboratories are being constructed outside Ottawa, and larger wind tunnels, both horizontal and vertical, are to be built, while a new model-testing basin will provide more adequate facilities for the study of ship and float design.

The National Research Council also maintained direct contact with similar scientific bodies in Great Britain, and since the beginning of the War the practice of exchanging scientific officers between Great Britain and Canada has been extended. The Sestion on Codes and Specifications is responsible for the preparation of commodity standards for Government Departments and for the development of a National Building Code as well as for general specification studies. The Research Plans and Publica. tions Section, in addition to the maintenance of the Library, is responsible for the publication of the Canadian Journal of Research, the preparation of bibliographies on scientific subjects, and translations, and also conducts a research advisory service. With the recall of the president, Major-General A. G. L. McNaughton, to active military service, Dean C. J. Mackenzie took over the duties of acting-president in October 1939.

Dealing with the work of the main research divisions, the Division of Biology and Agriculture continued its work on plant growth factors, including the hormone treatment of seeds. These tests, carried. out in co-operation with a number of organizations across Canada, indicated no appreciable benefit from such treatment of seeds when the hormone chemicals were incorporated in organic mercurial disinfectants

* National Research Council of Canada. Review of activities for the year endnd March 1940. N.R.C. No. 976. Pp. 155. 75 cents. or talc. Indolylacetic acid, however, proved effective in reducing injury by formaldehyde to germination in soil, and the dust method of applying synthetic hormone chemicals to plant cuttings had a further beneficial effect when the substances were used in combination with nutrient salts, sugar and organic mercurial disinfectants. Other work has been concorned with the propagation of forest trees from cittings. Satisfactory results have been obtained with plant hormones applied as dust or in a mixture of equal volumes of sand and peat humus. Further work has been carried out on the standardization of the experimental baking test as well as studies on malt quality and the modification of malt. Among the work carried out on food storage and transport, the investigation of the canning of poultry and the development of rancidity in frozen pork during storage, as well as the curing of bacon by smoking in view of the dearth of refrigerated shipping space available, may be mentioned. Other work has been concerned with the control of storage conditions and also with the storage of blood for transfusion purposes. Statistical studies have been made of the effect of dust seed treatment with indolylacetic acid on the growth and yield of barley under closely controlled conditions.

In the Division of Chemistry, a major project was concerned with the preparation of ethylene oxide by direct oxidation of ethylene by air over catalysts, and some catalysts have been prepared which show sufficiently high activity and specificity to indicate that-the process might be more practical than the chlorohydrin process for the manufacture of ethylene glycol. A new laboratory has been equipped for the study of synthetic resins and plastics, while the electrochemical laboratory has continued work on the corrosion of metals by used lubricating oils, the corrosion of metals and coatings by 'leaded' petrol under storage conditions, and a preliminary investigation of the corrosion of metals by hot and cold domestic tap waters and by softened laundry water. Investigations in the field of detergency as applied to laundering and dry-cleaning have been continued, as well as research on the possible harmful effects of certain textile finishing agents and methods of determining sizing and finishing compounds on cotton fabrics. In the Paint Laboratory, increasing attention has been given to protective coatings for use on aircraft, military vehicles and other equipment for war purposes.

The Division of Physies and Mechanical Engineering has been concerned with investigations on fatigue in aircraft propellers, the temperature control of refrigerator cars, development work on photographic apparatus for the Royal Canadian Air Force, and on the application of spectrochemical methods of analysis to agricultural problems.

of the associated and joint committees, the Associate Committee on Aeronautical Research has been responsible for further work on the cathode ray compass tests, on the oil dilution system for coldweather starting of aeroplane engines, the development of the apparatus to study vibrations in aireraft structures, fatigue of metal propellers and aircraft ski research.

Under the Advisory Committee on Field Crop Diseases, research in Alberta has indicated that seed 
treatment with formaldehyde is ineffective for preventing smut contamination. Copper carbonate and chloride were more effective, but the organic mercurial dusts were the best protectors. Research in Manitoba on liquid and dust fungicides for smut control showed that dust failed to control smut in oats and barley although the failure may have been due to the method of treatment given. Satisfactory control in wheat was obtained with solutions of organic mercurial compounds.

In work under the Associate Committee on Grain Research at the University of Alberta preliminary comparisons of the relatively injurious effects of the three organic mercury dusts, Now Improved Ceresan, Laytosan and Lunasan, on wheat indicated that the first was more likely to cause injury in overdoses than the others. Further evidence was obtained indicating that treatment of seed wheat with formaldehyde renders it more susceptible to mould damage than untreated wheat, although the damage was apparently reduced by addition of certain fungicidal dyes and organic mercurial compounds to formaldehyde solution.
Progress has been made with breeding projects aimed at the development of drought-resistant varieties of wheat. Work on the development of rust-resistant smooth awned barley of good malting property has continued.

Under the Associate Committee on Medical Research a study is being made of the relation of certain food factors to the development of cancer, and attempts to prepare a synthetic chemotherspeutic agent for the treatment of tuberculosis and studies of the relation of certain dietary deficiencies and physical factors to the development of arthritis are in progress.

Two meetings have been held of the Canadian Committee on Oceanography, established in March, 1938, while under the Associate Committee on Parasitology studies of the enzyme inhibitors of Ascaris and of the anthelmintic action of phenothiazine have been carried out. In addition to the studies of the anthelmintic action of phenothiazine in sheep, a method of administration has been worked out by critical testing and a test is being conducted on its effect on a flock of cull lambs.

\title{
THE HELIUM METHOD FOR DETERMINING THE AGE OF ROCKS
}

\author{
By N. B. KeEviL, \\ Department of Physics, University of Toronto
}

\begin{abstract}
$\mathrm{T}$ HE potentialities of radioactive methods of determining the ages of rocks, minerals and meteorites are so great that much time, money and effort have been expended in age research during the past decade. The supplement to the chemical method of the more elegant physical method of lead age determination from isotopic abundances has done much to establish confidence in the lead time-scale; but more hope has been held for the helium method because of its promised application to a great variety of geological materials rather than to a limited group of rare minerals.
\end{abstract}

It is now evident that the 'apparent age' or helium index calculated by the helium mothod is usually considerably lower than the age expected from geological and lead age data. Only in rare cases does the helium index seem to be concordant with the lead time-scale. This would not be so serious geologically if helium indexes were reasonably consistent, for it is not so much the absolute age as the sequence and relative time intervals which are of importance in geological problems. However, a survey of one hundred and fifty determinations on rocks has shown that there is only a one-to-one chance of finding the age of a basic rock within one geological period, that there is a still smaller chance of determining the age of a granitic rock, and that the results obtained for porphyries and lavas are meaningless from the point of view of age.

The discovery that differing values of the helium index are obtained for the different minerals constituent in rocks ${ }^{1}$ led to the theory that the low results were due to selective loss of helium in minerals. Results recently obtained for one hundred and fifty minerals have shown a variation in the ratio of experimental age (helium index, $I$ ) to the expected age, $A$, from mineral to mineral and from rock to rock. No one mineral has been found to give uniform results. Since more than ninety per cent of the four hundred age determinations made to date show lower values than expected, the explanation that the variations are due largely to non-uniform loss of helium seems a logical one, and hence $I / A$ may be termed the helium retentivity.

The results summarized in Table 1 show that the retentivity varies by a factor of 2500 , but if the high values are excluded, most of the average values, and the probable values of retentivity obtained from distribution curves, fall within the range $0 \cdot 3-0 \cdot 6$.

Table 1. Helium Retentivimas of Rocks and Minerals

\begin{tabular}{|c|c|c|c|c|c|}
\hline \multirow{2}{*}{$\begin{array}{l}\text { Type of } \\
\text { sample }\end{array}$} & \multirow{2}{*}{$\begin{array}{c}\text { No. of } \\
\text { samples } \\
\text { (Keevil) }\end{array}$} & \multicolumn{3}{|c|}{ Helium retentivity } & \multirow{2}{*}{$\begin{array}{l}\text { No. of } \\
\text { samples } \\
\text { (others) }\end{array}$} \\
\hline & & $\begin{array}{c}\text { Range } \\
\text { (Keevil) }\end{array}$ & $\begin{array}{c}\text { Average* } \\
\text { (Keevil) }\end{array}$ & $\begin{array}{c}\text { Average } \dagger \\
\text { (others) }\end{array}$ & \\
\hline $\begin{array}{c}\text { Granitic } \\
\text { rocks }\end{array}$ & 34 & $0 \cdot 02-0 \cdot 86$ & $0 \cdot 25$ & $0 \cdot 35$ & 6 \\
\hline Basic rocks & 18 & $0 \cdot 10-1.93$ & 0.44 & 0.45 & 69 \\
\hline $\begin{array}{l}\text { Porphyries } \\
\text { and lavas }\end{array}$ & 22 & $0 \cdot 01-1 \cdot 08$ & 0.12 & $0 \cdot 36$ & 9 \\
\hline Quartz & 14 & $0.04-1.22$ & 0.25 & & 0 \\
\hline Magnetite & 10 & $0 \cdot 24-12 \cdot 3$ & $0 \cdot 46$ & 0.93 & 18 \\
\hline Oxides & 6 & $0 \cdot 11-0 \cdot 59$ & $0 \cdot 32$ & 0.25 & 17 \\
\hline Feldspar & 25 & $0.02-0.46$ & $0 \cdot 20$ & & 2 \\
\hline Femics & 37 & $0 \cdot 05-3 \cdot 84$ & 0.57 & $0 \cdot 45$ & 4 \\
\hline Silleates & 22 & $0 \cdot 12-3: 63$ & 0.41 & $0 \cdot 34$ & 29 \\
\hline $\begin{array}{l}\text { Oxy-salts and } \\
\text { halides }\end{array}$ & 12 & $0 \cdot 03-24 \cdot 6$ & $0 \cdot 45$ & $0 \cdot 38$ & 10 \\
\hline
\end{tabular}

* Excluding 14 values indicating excess helium.

† Excluding 18 high values from data by Strutt, Holmes, Dubey, Kano, Davis, Lange, Urry, Goodman, and Hurley.

No significant disagreement exists between my results and data obtained by other observers. Rocks containing a glassy matrix are not comparable with crystalline rocks, since helium diffuses through glasses 